\title{
Activity Coefficients of Ammonia in Artificial Seawaters
}

\author{
Masunobu MAEDA* and Yoshiaki $\mathrm{KINJO}^{\dagger}$ \\ Received December 13, 1990 ; Accepted February 23, 1991
}

\begin{abstract}
Activity coefficients of ammonia in artificial seawaters at different salinities $(10-450 / 00)$ were measured at $25^{\circ} \mathrm{C}$ by a transpiration method. The activity coefficients(in molal units) were slightly less than unity over the measured salinity range, and increased with an increase in salinity to $350 / 00$ and then decreased. The activity coefficients of ammonia in the artificial seawaters were also estimated in terms of the pitzer theory and compared with the observed ones.
\end{abstract}

\section{INTRODUCTION}

The influence of electrolytes on the activity coefficients of nonelectrolytes in aqueous solutions is of both fundamental and applied interest. So far, the activity coefficients of ammonia have been measured in aqueous solutions of many salts. ${ }^{1,2)}$ However, the activity coefficients of ammonia in artificial seawaters do not seem to have been reported. Knowledge of the activity coefficients of ammonia in artificial seawaters is likely to be of value for the evaluation of the toxicity of ammonia in the marine environment, e.g. the toxic effects on marine fish. Data for the ammonia - ammonium ion equilibrium should also be indispensable

Department of Applied Chemistry, Nagoya Institute of Technology, Gokiso-cho, Showa-ku, Nagoya 466, Japan

+ Chemical Laboratory, College of Education, University of the Ryukyus, Okinawa 903-01, Japan

Key words: Activity coefficient of ammonia, Artificial seawaters, Transpiration method, Pitzer theory for the evaluation. Thus, recently, we have determined the dissociation constants of ammonium ion in artificial seawaters by glass-electrode potentiometry and compared the observed values with those predicted theoretically in terms of the Pitzer approach. ${ }^{3)}$ In the theoretical evaluation, however, due to the lack of the activity coefficients of ammonia in the artificial seawaters, we could not help employing the activity coefficients of ammonia in $\mathrm{NaCl}$ solutions at the same ionic strengths.

In the present work the activity coefficients of ammonia in artificial seawaters at different salinities(10 - 45 0/00) (here, salinity is defined as the weight in grams of dissolved salts in $1 \mathrm{~kg}$ of artificial seawaters) were measured at $25^{\circ} \mathrm{C}$ by a transpiration method. Since the introduction of $\mathrm{NH}_{3}$ into the artificial seawaters caused the precipitation of $\mathrm{Mg}(\mathrm{OH}) 2$, ammonium chloride was added so that no precipitation occurred. The activity coefficients of $\mathrm{NH}_{3}$ in the artificial seawaters were estimated according to the Pitzer approach, 4,5$)$ and 
Table 1 Molal composition of artificial seawaters at six salinities

\begin{tabular}{|c|c|c|c|c|c|c|}
\hline \multirow{2}{*}{$\begin{array}{l}\text { Component and ionic } \\
\text { strength } I\end{array}$} & \multicolumn{6}{|c|}{ Salinity/0/00 } \\
\hline & 10.19 & 25.21 & 30.14 & 35.05 & 39.90 & 44.72 \\
\hline $\mathrm{NaCl}$ & 0.1218 & 0.3059 & 0.3675 & 0.4296 & 0.4915 & 0.5537 \\
\hline $\mathrm{MgCl}_{2}$ & 0.01576 & 0.03956 & 0.04754 & 0.05557 & 0.06357 & 0.07162 \\
\hline $\mathrm{Na}_{2} \mathrm{SO}_{4}$ & 0.00835 & 0.02098 & 0.02521 & 0.02946 & 0.03371 & 0.03798 \\
\hline $\mathrm{CaCl}_{2}$ & 0.00308 & 0.00776 & 0.00932 & 0.01089 & 0.01247 & 0.01404 \\
\hline $\mathrm{KCl}$ & 0.00303 & 0.00759 & 0.00917 & 0.01066 & 0.01219 & 0.01374 \\
\hline$I$ & 0.2064 & 0.5184 & .0 .6228 & 0.7280 & 0.8329 & 0.9384 \\
\hline
\end{tabular}

compared with the observed ones.

\section{EXPERIMENTAL}

\subsection{Reagents}

All the reagents were of analytical grade and used without further purification.

\subsection{Preparation of artificial seawaters}

The artificial seawaters were prepared according to khoo et $a l^{6}{ }^{6)}$ The composition of the artificial seawaters at six salinities is given in Table 1. The ionic strengths were calculated in the usual way with neglect of ion - pairing. Ammonium chloride and ammonia were introduced in the seawaters so that the concentrations of the both reagents were ad-

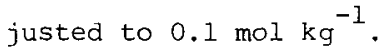

\subsection{Measurement of ammonia activities}

The transpiration experiments were carried out with the same glass apparatus as that used in the previous works. 3,7-9) It is schematically shown in Fig.l. vessel $A$ was filled with $0.1 \mathrm{~mol} \mathrm{dm}^{-3} \mathrm{NaOH}$ solution, and vessels $B$ and $C$ were charged with a sample solution (one of the "artificial seawaters" containing $0.1 \mathrm{~mol} \mathrm{\textrm {kg } ^ { - 1 }}$ $\mathrm{NH}_{4} \mathrm{Cl}$ and $\mathrm{NH}_{3}$, or $0.1 \mathrm{~mol} \mathrm{~kg} \mathrm{NH}_{4} \mathrm{Cl}$ aq-

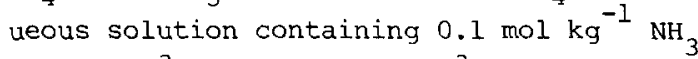

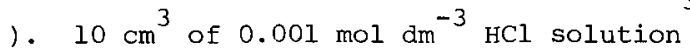

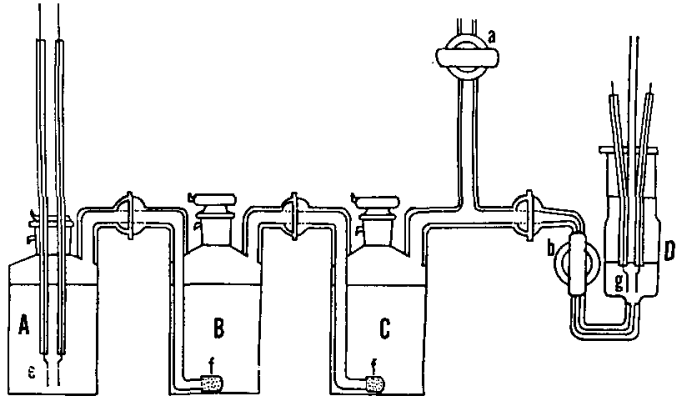

Fig.l Apparatus for measurement of ammonia activity

e: platinum plates, f: sintered glass, g: platinum plates coated with platinum black

were introduced in conductivity cell $D$. The whole apparatus was immersed in a water thermostat kept at $25.00 \pm 0.01^{\circ} \mathrm{C}$. First, a carrier gas (mixture of $\mathrm{H}_{2}$ and $\mathrm{O}_{2}$ ) was generated by electrolysis in vessel $A$ with stopcock $a$ open and stopcock $b$ closed until the empty spaces and the tubes were saturated with the $\mathrm{NH}_{3}$ gas. Then, in a condition of stopcock $a$ being closed and stopcock $b$ being open the electrolysis for the generation of the carrier gas was carried out in small steps so that the $\mathrm{NH}_{3}$ gas transpired by the carrier gas was absorbed in the $\mathrm{HCl}$ solution 
in cell $D$ with the conductivity of the $\mathrm{HCl}$ solution being measured in each step. The electrolysis was carried out by means of a coulometer(Metrohm, E524) and the conductivity measurement with an ac bridge (Delica, model DlS). The $\mathrm{NH}_{3}$ concentration in a sample solution in vessel $C$ before and after the experiment was measured by acid - base titration to ascertain the invariance of the $\mathrm{NH}_{3}$ concentration during the experiment.

\section{RESULTS AND DISCUSSION}

\subsection{Activity coefficient of ammonia.}

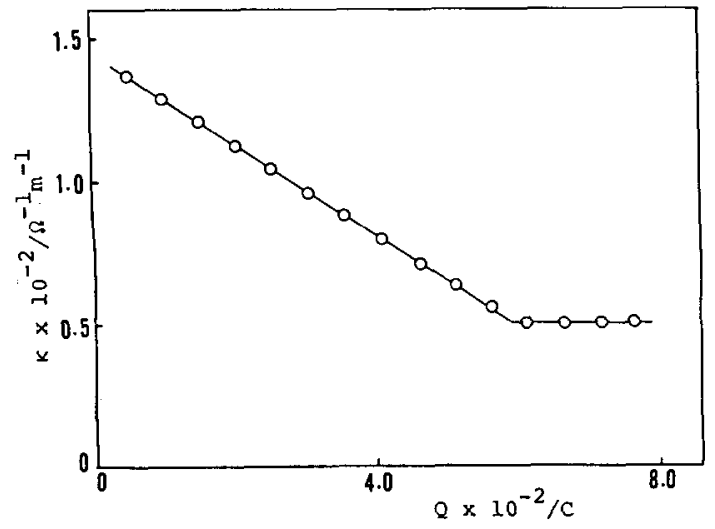

Fig.2 Plot of conductivity $K$ against quantity of electricity $Q$ for $0.1 \mathrm{~mol} \mathrm{\textrm {kg } ^ { - 1 }}$ $\mathrm{NH}_{4} \mathrm{Cl}$ aqueous solution

Experimental plots of the conductivities $K$ against the quantities of electricity passed $Q$ (for generation of the carrier

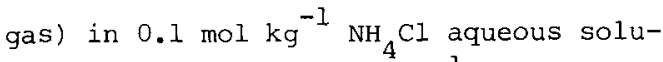
tion containing 0.1 mol $\mathrm{kg}^{-1} \mathrm{NH}_{3}$, which is taken as a standard in the evaluation of the activity coefficients of ammonia in the artificial seawaters, are illustrated in Fig.2. The similar plots were obtained for the "artificial seawaters"

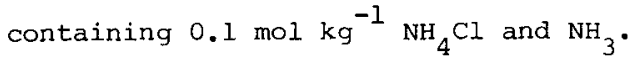

The amount of electricity passed $Q_{e}$ for the transpiration of $\mathrm{NH}_{3}$ needed to neutral-

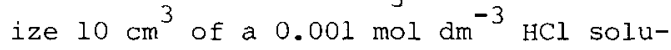
tion was calculated from the slope change. As was the case in the evaluation of the activity coefficients of ammonia in various electrolyte solutions, ${ }^{3,7-9)}$ the activity coefficients of ammonia, $\gamma_{\mathrm{NH}_{3}}$, in the artificial seawaters with the composition given in Table 1 were evaluated according to Eq. (1) by use of the $Q_{e}$ values and the ammonia concentrations $C_{\mathrm{NH}_{3}}$ (in molal units) in 0.1 mol $\mathrm{kg}^{-1} \mathrm{NH}_{4} \mathrm{Cl}$ aqueous solution and in the "artificial seawaters" containing

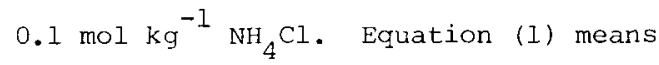
that the subtraction of contributions due to $\mathrm{NH}_{3}-\mathrm{NH}_{4} \mathrm{Cl}$ and $\mathrm{NH}_{3}-\mathrm{NH}_{3}$ interactions, which are observed in 0.1 mol $\mathrm{kg}^{-1} \mathrm{NH}_{4} \mathrm{Cl}$ aqueous solution containing $0.1 \mathrm{~mol} \mathrm{~kg}^{-1}$ $\mathrm{NH}_{3}$, from the activity coefficients of ammonia in the "artificial seawaters" containing 0.1 mol $\mathrm{kg}^{-1} \mathrm{NH}_{4} \mathrm{Cl}$ and $\mathrm{NH}_{3}$ leads to the activity coefficients of ammonia, $\gamma_{\mathrm{NH}_{3}}$, in the artificial seawaters.

$$
Y_{\mathrm{NH}_{3}}=\left(Q_{\mathrm{e}}^{0} / Q_{\mathrm{e}}\right)\left(C_{\mathrm{NH}_{3}}^{0} / C_{\mathrm{NH}_{3}}\right)
$$

in which the superscript 0 is for 0.1

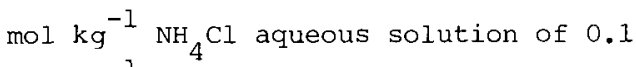
$\operatorname{mol~} \mathrm{kg}^{-1} \mathrm{NH}_{3}$.

The $\gamma_{\mathrm{NH}_{3}}$ values in the artificial seawaters thus determined are tabulated in Table 2. Evidently the $\gamma_{\mathrm{NH}_{3}}$ values in the artificial seawaters are less than unity over the measured salinity range, and increase with increasing salinity to $350 / 00$ and then decrease. The $\gamma_{\mathrm{NH}_{3}}$ values in the artificial seawaters are much smaller than those in the $\mathrm{NaCl}$ solutions with the same ionic strengths as those in the artificial seawaters, $i . e .$, the values in the $\mathrm{NaCl}$ solutions are larger than unity, and in- 
Table 2 Activity coefficients of ammonia $\gamma_{\mathrm{NH}_{3}}$ (in molal units) at $25^{\circ} \mathrm{C}$ observed and estimated in artificial seawaters with different ${ }^{3}$ salinities(ionic strengths) and those observed in sodium chloride solutions with different ionic strengths ${ }^{3), *}$ )

\begin{tabular}{|c|c|c|c|c|}
\hline \multirow[t]{2}{*}{ Salinity $/ 0 / 00$ (ionic strength) } & \multicolumn{2}{|c|}{${ }^{Y} \mathrm{NH}_{3}$} & \multirow{2}{*}{$\begin{array}{l}\text { Ionic strength } \\
\text { of } \mathrm{NaCl}\end{array}$} & \multirow[t]{2}{*}{$\gamma_{\mathrm{NH}_{3}}$} \\
\hline & Obsd & Est & & \\
\hline $10.19(0.2064)$ & $0.978_{6}$ & $1.00_{0}$ & & \\
\hline $25.21(0.5184)$ & $0.981_{4}$ & $1.00_{1}$ & 0.516 & 1.040 \\
\hline $30.14(0.6228)$ & $0.984_{6}$ & $1.00_{1}$ & 0.621 & 1.048 \\
\hline $35.05(0.7280)$ & $0.987_{7}$ & $1.00_{1}$ & 0.725 & $1.05_{7}$ \\
\hline $39.90(0.8329)$ & $0.978_{4}$ & $1.00_{1}$ & 0.829 & $1.06_{6}$ \\
\hline $44.72(0.9384)$ & $0.971_{7}$ & $1.00_{2}$ & 0.966 & 1.077 \\
\hline
\end{tabular}

*) The ionic strengths in the NaCl solutions are not strictly in agreement with those in the artificial seawaters.

crease with increasing NaCl concentration. The fact that the $\gamma_{\mathrm{NH}_{3}}$ values in the artificial seawaters are much smaller than those in the $\mathrm{NaCl}$ solutions may be asscribed mainly to the difference in hydration extent between $\mathrm{Na}^{+}$and $\mathrm{Mg}^{2+}$ ions. The $\mathrm{Mg}^{2+}$ ion may be more strongly hydrated than the $\mathrm{Na}^{+}$ion, because the former has a smaller ionic radius and a higher electric charge than the latter. Thus, the coordinated water molecules to the $\mathrm{Mg}^{2+}$ ion are more strongly oriented with their protons outward and the attraction between these protons and ammonia molecules may then be stronger, which could lead to the lower activity coefficients in the artificial seawaters than in the $\mathrm{NaCl}$ solutions. The increase of the $\gamma_{\mathrm{NH}_{3}}$ values with increasing $\mathrm{NaCl}$ concentration in the $\mathrm{NaCl}$ solutions may be explained on the basis of the competition of the following two phenomena (a) and (b). The rise in $\mathrm{NaCl}$ concentration may bring about (a) the increase in interaction between protons in water molecules coordinated to $\mathrm{Na}^{+}$ions and ammonia molecules, which should result in the reduction of the $\gamma_{\mathrm{NH}_{3}}$ values, and (b) the decrease of the so $-{ }^{3}$ called free water, in which ammonia molecules should be dissolved, due to the hydration of $\mathrm{Na}^{+}$ions, which should lead to the enhancement of the $\gamma_{\mathrm{NH}_{3}}$ value. Thus, it may be said that the increase of the $\gamma_{\mathrm{NH}_{3}}$ values in the $\mathrm{NaCl}$ solutions is ascribed ${ }^{3}$ to the fortuitous superiority of the phenomenon (b) over (a) in extent.

3.2 Comparison between observed and estimated $\gamma_{\mathrm{NH}_{3}}$ values in artificial seawaters Table 3 Interaction parameters for $\mathrm{NH}_{3}$ in Pitzer equation

\begin{tabular}{lll}
\hline Ion $i$ & $\lambda_{\mathrm{NH}_{3} i}$ & $\mu_{\mathrm{NH}_{3} i \mathrm{Cl}}$ \\
\hline $\mathrm{Na}^{+}$ & 0.0175 & \\
$\mathrm{~K}^{+}$ & 0.0454 & \\
$\mathrm{Mg}^{2+}$ & -0.21 & -0.00134 \\
$\mathrm{Ca}^{2+}$ & -0.081 & \\
$\mathrm{Cl}^{-}$ & 0 (defined) & \\
$\mathrm{SO}_{4}^{2-}$ & 0.140 & \\
\hline
\end{tabular}


In Pitzer's model ${ }^{10)}$ the equation for the activity coefficient of ammonia in the mixed electrolyte solution is given by Eq. (2)

$$
\begin{aligned}
\ln \gamma_{\mathrm{NH}_{3}}= & 2 \sum_{c} m_{c} \lambda_{\mathrm{NH}_{3} c}+2 \sum_{a} m_{a} \lambda_{\mathrm{NH}_{3} a}+ \\
& 3 \sum \sum m_{i} m_{j} \mu_{\mathrm{NH}_{3}} i j
\end{aligned}
$$

where $\lambda$ and $\mu$ are second and third virial coefficients for ion - $\mathrm{NH}_{3}$ interactions, respectively, which are independent of ionic strength. $m_{i}$ and $m_{j}$ are molalities of species $i$ and $j$, and the subscripts $c$ and $a$ represent cations and anions, repectively.

Recently, Clegg and Brimblecombe 2 ) have calculated the values for $\lambda_{\mathrm{NH}_{3} \mathrm{c}}$ ' $\lambda_{\mathrm{NH}_{3} \alpha^{\prime}}$ and $\mu_{\mathrm{NH}_{3} i j}$ by using partial ${ }^{3}$ pressurê, salt solubility, and partitioning data for aqueous electrolyte solutions containing $\mathrm{NH}_{3}$. The $\gamma_{\mathrm{NH}_{3}}$ values in the artificial seawaters were estimated according to Eq. (2) by use of their $\lambda$ and $\mu$ values given in Table 3 . The results are listed in Table 2, together with the observed ones for comparison. The estimated $\gamma_{\mathrm{NH}_{3}}$ values are obviously close to unity with indication of slight increase with salinity. This tendency differs from that in the observed $\gamma_{\mathrm{NH}_{3}}$ values. The discrepancy may be ascribed partly to the fact that for want of the $\mu$ data, as is apparent from Table 3, the theoretical calculations have been made with almost no $\mu$ value.

In conclusion, it may be said that the $\gamma_{\mathrm{NH}_{3}}$ values in the artificial seawaters are ${ }^{3}$ slightly less than unity over the mea- sured salinity range (10 - 45 0/00), and increase with increasing salinity up to $350 / 00$ and then decrease, and that the employment of $\gamma_{\mathrm{NH}_{3}}$ values in $\mathrm{NaCl}$ solutions as those in artificial seawaters which have the same ionic strengths as the NaCl solutions will lead to inaccurate results.

\section{REFERENCES}

1) F. A. Long and W. F. McDevit, Chem. Rev., 51, 119 (1952).

2) S. L. Clegg and P. Brimblecombe, $J$. Phys. Chem., 93, 7237 (1989) and references cited therein.

3) M. Maeda, M. Hayashi, S. Ikeda, Y. Kinjo, and K. Ito, Buzl. Chem. Soc. Jpn., 61, 2047 (1987).

4) K. S. Pitzer, J. Phys. Chem., 77, 268 (1973).

5) K. S. Pitzer, Activity Coefficients in Electrolyte Solutions (ed. R. M. Pytkowicz), CRC Press, Boca Raton, FL, 1979, Chapter 7 and references cited therein.

6) K. H. Khoo, C. H. Culberson, and R. G. Bates, J. Solution Chem., 6, 281 (1977).

7) M. Maeda, O. Hisada, K. Ikedo, H. Masuda, K. Ito, and Y. Kinjo, J. Phys. Chem., 92, 6404 (1988).

8) M. Maeda, O. Hisada, K. Ito, and Y. kinjo, J. Chem. Soc. Faraday Trans. I, 85,2555 (1989).

9) M. Maeda, Y. Kinjo, O. Hisada, and K. Ito, J. Solution Chem., 19, 1019 (1990).

10) K. S. Pitzer and L. F. Silvester, J. Solution Chem., 5, 269 (1976). 